EMBRYARIDDLE
Aeronautical University

SCHOLARLY COMMONS

\section{International Journal of Aviation,} Aeronautics, and Aerospace

\title{
Application of artificial neural networks for the prediction of aluminium agglomeration processes
}

\author{
TEJASVI K \\ DEFENCE RESEARCH AND DEVELOPMENT ORGANISATION, tejasvichem@gmail.com \\ Y PYDI SETTY \\ ypydisetty@yahoo.com \\ VEMANA VENKATESWARA RAO \\ VEMANAVRAO@GMAIL.COM \\ KALYAN CHAKARVARTHY \\ vkchakarvathy75@gmail.com
}

Follow this and additional works at: https://commons.erau.edu/ijaaa

Part of the Propulsion and Power Commons

\section{Scholarly Commons Citation}

K, T., SETTY, Y., VENKATESWARA RAO, V., \& CHAKARVARTHY, K. (2018). Application of artificial neural networks for the prediction of aluminium agglomeration processes. International Journal of Aviation, Aeronautics, and Aerospace, 5(5). https://doi.org/10.15394/ijaaa.2018.1296

This Article is brought to you for free and open access by the Journals at Scholarly Commons. It has been accepted for inclusion in International Journal of Aviation, Aeronautics, and Aerospace by an authorized administrator of Scholarly Commons. For more information, please contact commons@erau.edu. 


\section{INTRODUCTION}

Aluminum has been used as a fuel additive in rocket propellants since the 1950s. Its use as a fuel is widespread ranging from large scale solid rocket boosters to hobbyist rocket motors. Aluminum powder raises the specific impulse $\left(\mathrm{I}_{\mathrm{sp}}\right)$ through the product molecular weights and increased flame temperature (Bucher, Ernst, \& Dryer, 2000). It also suppresses high-frequency combustion instabilities through viscous particle damping (Price, 1965). Aluminized ammonium perchlorate composite propellants (APCPs) form large molten aluminum ( $\mathrm{Al}$ ) agglomerates leading to incomplete combustion and two-phase flow losses (Beckstead, 2004; Hermsen, 1999; Price \& Sigman, 1999). These large molten droplets (LMD) result from the coalescence of multiple Al particles and they are often an order of magnitude larger than the initial constituent particle size (Price \& Sigman, 1999; Sippel, Son, \& Groven, 2013). The mechanism of aluminum agglomeration and combustion has studied before to understand the particle dynamics and phenomena in the gas phase (Cheung \& Cohen, 1964; Churchill, Fleming, \& Cohen, 1974; Hermsen, 1999; Povinelli \& Rosenstein, 1964; Sambamurthi, Price, \& Sigman, 1984; Sippel, Son, Groven, Zhang, \& Dreizin, 2014). Currently, techniques for sizing Al agglomerations in APCPs include phase Doppler anemometry (Laredo \& Netzer, 1993), laser diffraction (Laredo, McCrorie, Vaughn, \& Netzer, 1994), particle collection (Laredo et al, 1994; Price \& Sigman, 1999; Sippel et al. 2014), videography (Bucher et al., 2000; Karasev et al., 2004), schlieren (Cauty, Erades, \& Desse, 2011), shadowgraphy (Karasev et al., 2004), holography (Butler \& Netzer, 1988; Faber \& Netzer, 1983; Powers \& Netzer, 1992; Walker \&Netzer, 1987), and digital inline holography (DIH) (Guildenbecher et al., 2014).

According to the literature (Babuk, 1998; Babuk, Vasilyev, \& Malakhov, 1999; De Luca, 2007; Glotov, 2000; Price, Sigman, Sambamurthi, \& Park, 1982), the aggregation process for micrometric aluminium powder inside a solid propellant comprises several steps: first is a pre-aggregation within the space left free by the larger oxidizer particle, called "pocket" and "bridge." The pockets are connected together by the bridges as shown in Figure 1. 


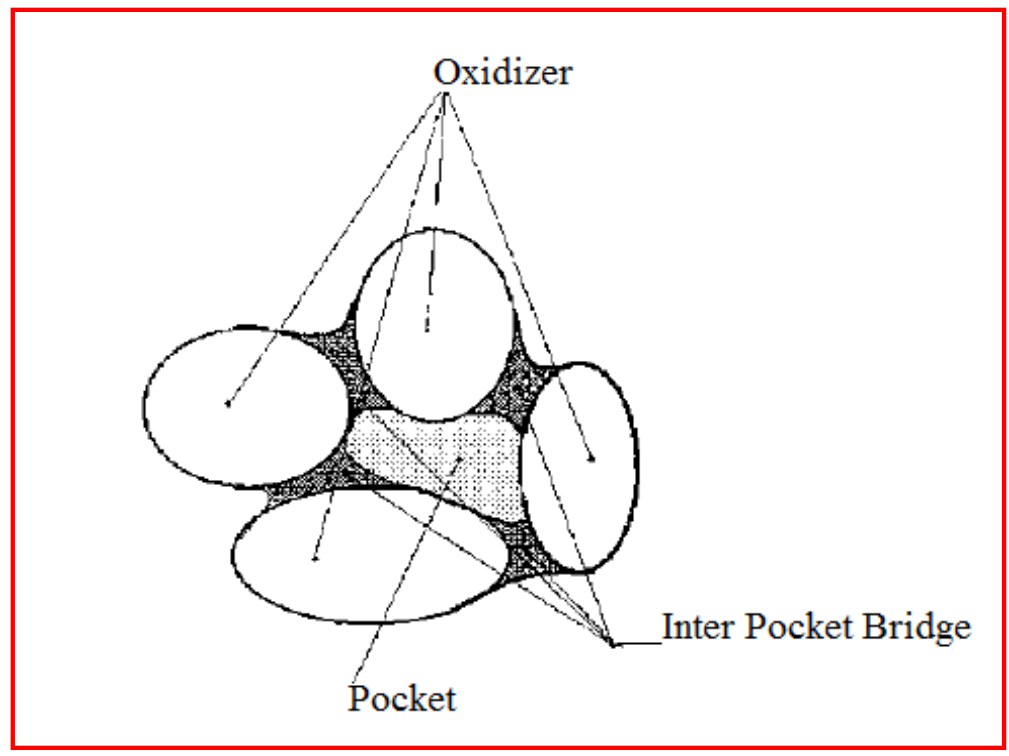

Figure 1. Structure of Pocket. Adapted from "Condensed Combustion Products at the Burning Surface of Aluminized Solid Propellant” by V A. Babuk, V. A.

Vasilyev, and M. S. Malakhov, 1999, Journal of Propulsion and Power, 15, 783793.

The second step begins when the burning surface reaches these pockets. Babuk et al (1999) called this structure the skeleton layer. Then, this structure collapses into a bigger metal sphere, the agglomerates. Most of the emerged aggregates are in liquid state, and the aggregates continue their growth attaching themselves to other neighboring pockets. As a third step the aggregates (that are not yet spherical, but like a coral), reach the temperature of ignition, showing the first inflammation and conclude the transition between aggregate and agglomerate (exhibiting the typical structure represented in Figure 2). 


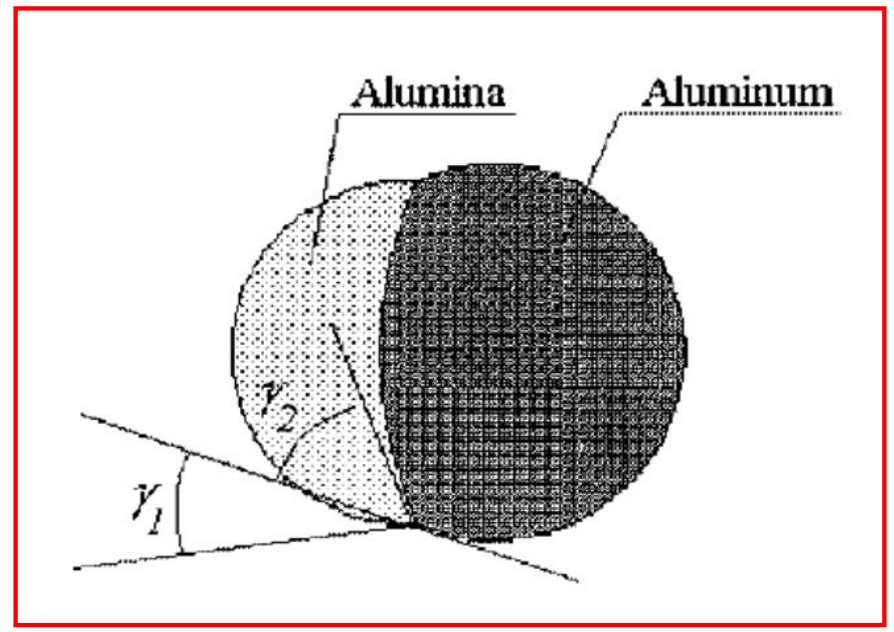

[ $\gamma_{1}$ and $\gamma_{2}$ are angles of wetting, for $6 \mathrm{MPa}, \gamma_{1}=26 \mathrm{deg}$ and $\left.\gamma_{2}=41 \mathrm{deg}\right]$

Figure 2. Structure of agglomerate. Adapted from "Condensed Combustion Products at the Burning Surface of Aluminized Solid Propellant" by V A. Babuk, V. A. Vasilyev, and M. S. Malakhov, 1999, Journal of Propulsion and Power, 15, 783-793.

Then they can detach, or begin moving on the burning surface where they collide with other agglomerates. Collisions between agglomerates can be considered as the main growth factor. In general, the agglomeration effect depends on the pressure (Dossi, 2010) (higher pressure means smaller agglomerates), the temperature, the oxygen balance of the propellant (which influences the burning), the type of burning surface--a liquid layer impedes the detachment with the consequence of further growing of the agglomerate (DeLuca, 2013), the mean size of the original metal particles, the size of the oxidizer prills-which directly influences the size of the pockets, and the residence time on the burning surface before the detachment (De Luca, 2007). When the agglomerates detach the determination of the maximum diameter is possible. A number of theoretical models have been developed to predict the agglomerate size in solid composite propellants. Salita (1994), Beckstead (1977), Willoughby, Baker, and Hermsen (1971), and Liu (2005) have proposed an empirical model of aluminum agglomeration with characteristic parameters linked to propellant formulation or burning rate. This empirical model is based completely on experimental data and the extrapolation to other propellants is certainly questionable. Cohen (1983) and Grigorev et al. (1981) have given a pocket model of aluminum agglomeration in relation to the size of the region between adjacent coarse oxidizer particles in the propellant microstructure. According to this model, all aluminum particles located inside a pocket area form only a single agglomerate. Gallier (2009) has also 
proposed a pocket model essentially relaxing simple assumptions of previous pocket models on propellant structure by accounting for an actual random structure obtained by packing. Jackson, Najjar, and Buckmaster (2005) have used a computer-generated 3D pack of particles to simulate the propellant microstructure, and giving agglomerate size distribution on burning surface. Little literature is available on the study of the aluminum agglomeration of aluminized propellants under operation pressure, previous studies (Babuk et al., 2005; Liu, 2005; Sambamurthi et al., 1984) have not stripped the influence of quench distances and pressure on agglomeration.

Artificial Neural Networks (ANN) can be deemed as powerful tools for modeling complex systems. Unlike the more commonly used analytical methods, the ANN is not dependent on particular functional relationships, requiring no assumptions regarding the distributional properties of the data and no a priori understanding of variable relationships. This independence makes the Artificial Neural Networks (ANN) a potentially powerful modeling tool for exploring nonlinear complex problems. Neural networks (NNs) are non-linear mapping structures inspired by the function of the human brain. They are considered powerful modeling tools especially for data with unknown underlying relationships. NNs consist of computational elements called "neurons," operating in parallel, connected by links with variable weights which are typically adapted during the learning process (Mitchell, 1997; Patterson, 1996). The number of neurons and the scheme of connection with each other can vary. ANN can be presented often as neurons formed in layers. The neurons in a layer are not connected with each other, but they are connected with neurons of the previous and next layers by the principle "each with each." Haykin (1999) defined neural network as a massively parallel distributed processor that has a natural propensity for storing experiential knowledge and making it available for use. It resembles the brain in two respects - knowledge is acquired by the network through a learning process, and - interneuron connection strengths known as synaptic weights are used to store the knowledge. The neural network approach is a branch of artificial intelligence. The ANN is based on a model of the human neurological system that consists of basic computing elements (neurons) interconnected together (Figure 3). 


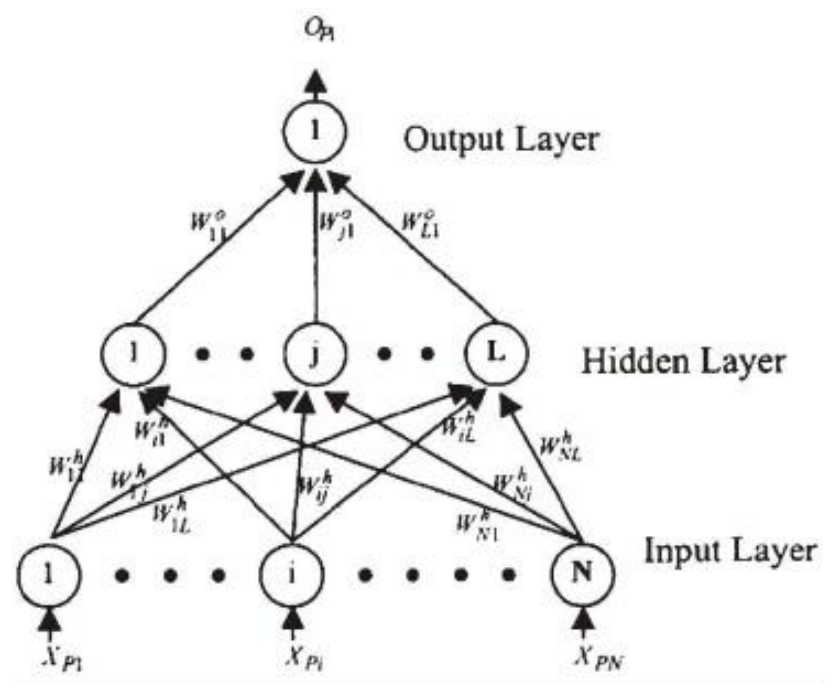

Figure 3.A neural networks (ANN is an interconnected group of nodes). Adapted from "Neural Networks: A Comprehensive Foundation" by S. Haykin, 1999, Upper Saddle River, NJ: Prentice Hall.

The used model was a standard, five-layer, back propagation, neural network with input nodes $(\mathrm{N})$, hidden nodes $(\mathrm{L})$, and output node(I). The neurons layer is determined by its weight matrix, a bias vector and a transfer function. The trial and error method is used to determine actual number of hidden neurons. The propagation of information flows through hidden layer from the input layer to the outer layer. During ANN training, a training tool compares the output signals to known aimed values, calculates the error, modifies the weights of synapses by means of the algorithm "back propagation of errors" and iterates the training cycle persistently till a suitable target values is achieved. A usual range of training cycles may be quite a thousand. The back propagation (BP) algorithm is one of the most preeminent training algorithms for multilayer neural networks. BP is a parentage technique to minimize the error $\mathrm{E}$ for a particular training pattern.

In this work, a feed forward back propagation neural network is used to predict the agglomerate diameter based on the input parameters such as Quench Distance (QD) and Pressure (P).

\section{MATERIALS AND METHODS}

This section is divided into two subsections: First, the propellant samples, set-up, collection and measurement of agglomerates are presented and finally the modeling with artificial neural network was explained.

Samples, quench set-up, agglomerate collection and measurement

The propellant samples formulations include ammonium perchlorate (AP, $\mathrm{NH}_{4} \mathrm{ClO}_{4}$ ) as an oxidizer, aluminum particles (micrometric aluminium for P1 to 
P5 propellants \& ultra-fine aluminium for P6 propellant) as a metal fuel, a binder (HTPB) and the additives. Table 1 presents the sample propellant compositions.

Table 1

Propellant Compositions

\begin{tabular}{|c|c|c|c|}
\hline $\begin{array}{l}\text { Propellant } \\
\text { Identity }\end{array}$ & \multicolumn{2}{|c|}{ Aluminium } & $\begin{array}{c}\text { Binder/Curing } \\
\text { Agent }\end{array}$ \\
\hline & $\begin{array}{l}\text { Size } \\
(\mu \mathrm{m})\end{array}$ & $\%$ & \\
\hline P1 & \multirow{5}{*}{18.0} & & \multirow{5}{*}{ HTPB/TDI } \\
\hline $\mathbf{P 2}$ & & & \\
\hline P3 & & $\begin{array}{l}1 \\
8\end{array}$ & \\
\hline P4 & & 4 & \\
\hline P5 & & $\begin{array}{l}1 \\
5\end{array}$ & \\
\hline P6 & 0.44 & $\begin{array}{l}1 \\
8\end{array}$ & HTPB/TDI+IPDI \\
\hline
\end{tabular}

Propellant samples (cylindrical discs) of $25 \mathrm{~mm}$ diameter and $5 \mathrm{~mm}$ thickness are prepared after mixing and curing at $50^{\circ} \mathrm{C}$ for 7 days for six propellants respectively. Propellant samples are tested in a quench set up to collect the aluminium agglomerates. The experiment includes six propellants at four different pressures and six different distances. The collected aluminum agglomerates are more than the parent aluminium size. The particles are identified digitally and their edges are detected using computer software. The pixels contained within the detected edges are used to find an equivalent diameter of a circular projection of each particle, to obtain its size for a given magnification using the pixel distances. Figure 4 shows particles labeled as part of analysis of P6 propellant. These identified agglomerate images are analyzed using ImageJ (a particle and image analysis tool) software to determine agglomerate diameter followed by arithmetic mean diameter (AMD) based on the following definition:

$$
D_{10}=\Sigma\left(n_{\mathrm{i}} \mathrm{d}_{\mathrm{i}}\right) /\left(n_{\mathrm{i}}\right)
$$

Where $n_{i}$ refers to number of particles with diameter $d_{i}$ and $d_{i}$ is nominal diameter of $i^{\text {th }}$ particle. 


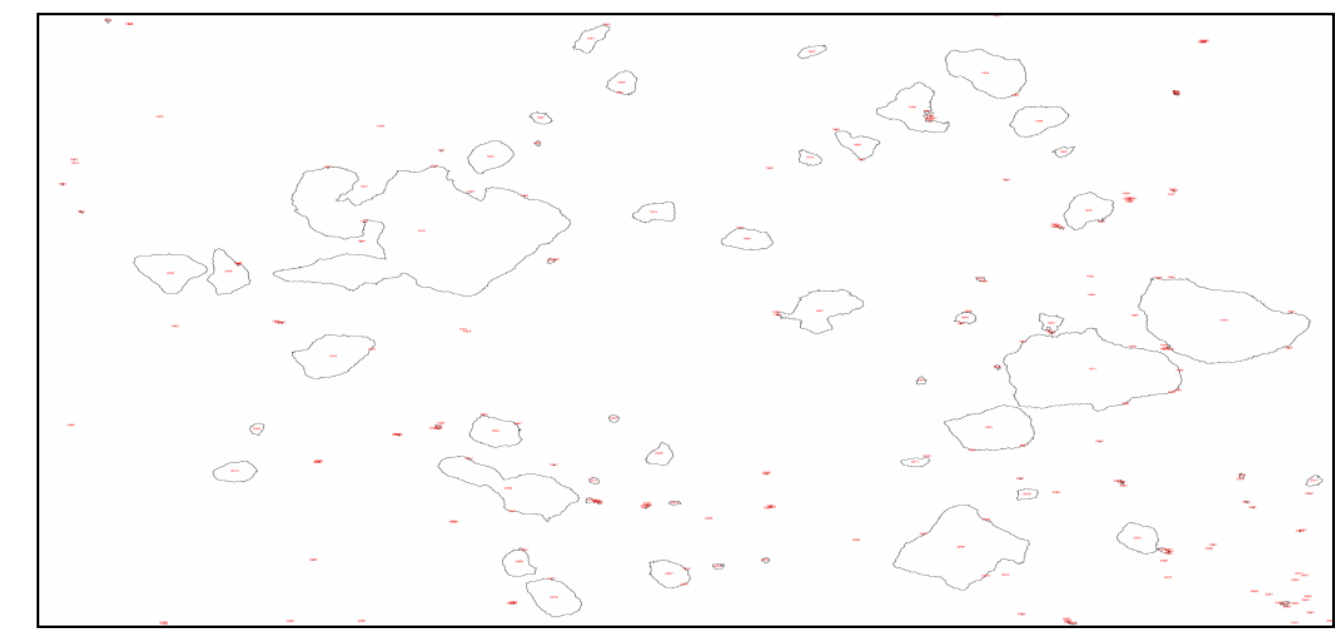

Figure 4. Particles counted as part of analysis of P6 Propellant.

\section{Modeling with Artificial Neural Network}

Combustion of aluminized solid propellants introduces the well-known undesirable agglomeration development. A significant attempt has been dedicated to assessing and predicting the size of agglomerates ejected from the burning surface. A comprehensive overview of agglomeration modeling was presented by Beckstead (2004/2005). The main aim of the neural network is to convert different data inputs toget significant outputs. The various types of neural network approaches are present, in which Multilayer Perception (MLP); a feed forward back propagation neural network is the mostcommonly used ANN approach. Back propagation is an algorithm which is commonly applied for training. During training the data, the weights are adjusted to decree empirical correlation between input and output variables in the system. Neuron models with some inputs should be coupled with weights ' $w$ ' in a multilayer neural network. The sum of these weighted inputs andthe bias forms the input to the transfer function ' $F$ ' which is as shown in Eqn. (1)

$$
Y=F(x, w)(1)
$$

where $\mathrm{Y}$ is output, $\mathrm{F}$ is transfer function, $\mathrm{x}$ is input, and $\mathrm{w}$ is the weight. Sigmoid transfer function is preferably used by neuron to generate the output. Feed forward networks have one input layer, one or multiple hidden layers of neurons followed by an output layer. The outcome of performance analysis for feed forward network is based on the estimation of Mean Square Error (MSE); which is the average of the squared error between the network outputs ' $a$ ' and the target outputs ' $t$ ', in which suffixes indicate the number of observations, defined by Eqn. (2) given below. Schematic flow diagram of the artificial neural network developed is shown Figure 5. 
(2) MSE $\left.\square \square \square \square 1 / N \square \square \square \mathrm{t}_{\mathrm{i}}-\mathrm{a}_{\mathrm{i}}\right)^{2}$

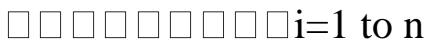

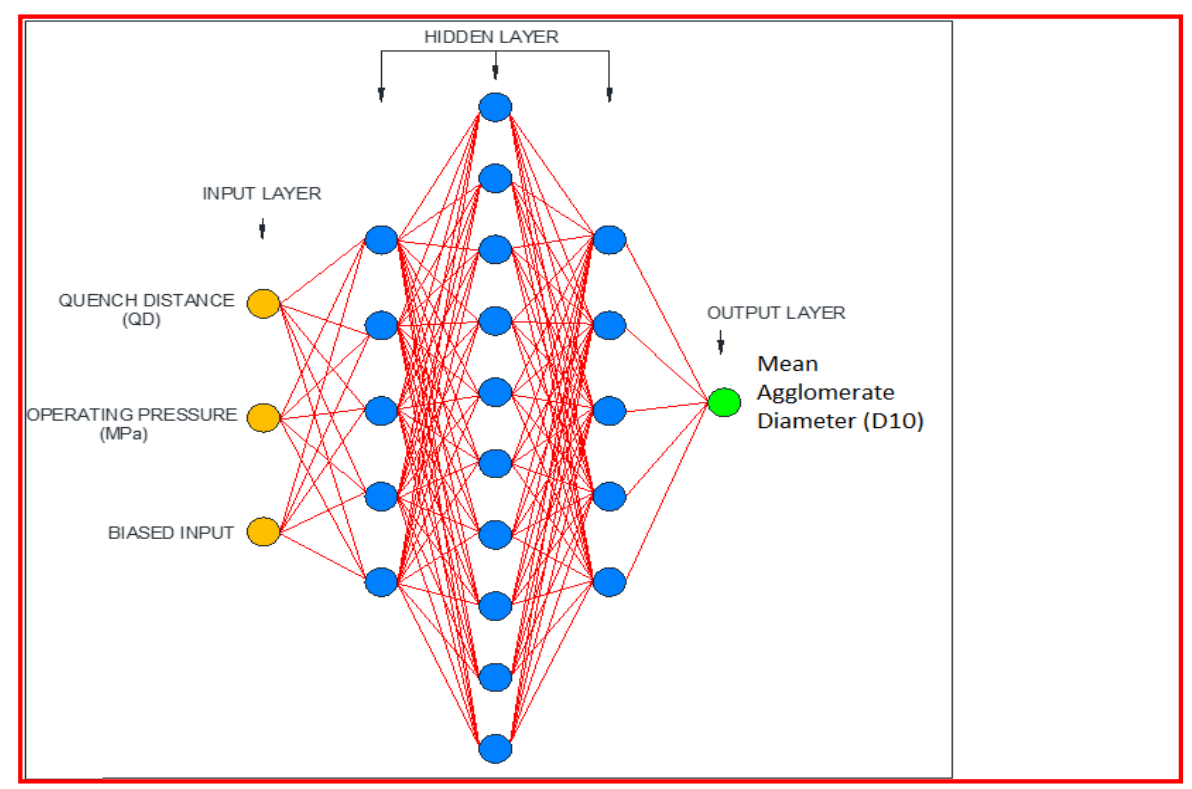

Figure 5. A typical representation of ANN structure.

The Multilayer Perception (MLP) architecture, thus obtained has one input layer with three input node values, one hidden layer with three hidden node values or neurons, and one output layer with one output node values. All neurons are associated with different weights. ANN model has been developed using a total of 144 experimental data. Out of these 144 experiments, $84 \%$ data were used for training of the model; $16 \%$ was used for testing of the model.

The start of the training phase includes neural networks activation with multiple input vectors and the output was calculated. The error values are produced after comparing calculated outputs to the target values. Each weight was adjusted according to the magnitude of the error to reduce the total error. The new sets of outputs are obtained after re-calculation using the adjusted weights. These successively were compared with the targets, and the weights were adjusted again. This method was repeated until an appropriate criterion was reached. The criteria used in this paper is the total error, (i.e. error based on the mean squared error (MSE) between the networkoutput and target), to terminate the training 
session. The resultant model at the end of the training phase was used in the testing phase.

\section{ANN modeling}

\section{RESULTS AND DISCUSSION}

In the present work, a 5-layer feed forward neural network (3-5-10-5-1) is intended by changing the two different operational process variables to obtain agglomerate diameter, viz, Quench distance, and Pressure, and the results were evaluated. The Multilayer Perception (MLP) has one input layer associated with three nodes, three hidden layers associated with first layer having 5 neurons, the 2nd layer having 10 neurons, the $3^{\text {rd }}$ having 5 neurons, and one output layer with one output node value. All these neurons/nodes were coupled with different weights. In the present study, ANN model has been planned by carrying a total number of 24 runs for each label propellant used for training the network. The ANN has been implemented using Matlab script. All the input variable and output variable were normalized in the range of $(0,1)$ before starting the training of data. A multilayer feed forward, back propagation neural network was used with sigmoid as a transfer function at learning rate of 0.5 , momentum rate of 0.25 , and 1000 epochs. The ANN design was trained exploitation stopping criterion as one thousand iterations. Tables 2 to 7 gives experimental data and predicted data from ANN for P1 to P6 propellants.

\section{Performance measurement of Neural Network for Experimental Data}

To determine the optimal architecture, 6 different networks with different number of layers and neurons in the hidden layer were designed and tested for determination of agglomerate diameter. The performance capabilities of each network were examined based on the mean squared error between the network predictions and the experimental values using the test and the entire dataset. From Tables 2 to 7, it was identified that the network with three hidden layers and 5 10 - 5 neurons in each layer (3-5-10-5-5) produced the best performance for each of the output parameters. Further, the average percentage error was also less than $\pm 3 \%$ which means the ANN predicted results were very much closer to the experimental (actual) results shown in Figures 6 - 11. It revealed that the prediction of ANN model was found to be in good agreement with experimental data.

\section{Effect of quench distance on agglomerate diameter}

The distance between the propellant and the surface of quench liquid is the quench distance. The particles from the burning propellant travel this distance before being quenched in the liquid. The results showed the dependence of agglomerate size on quench distance. At lesser quench distance, the unburned aluminium content was significantly higher which indicates additional combustion is occurring and hence formation of larger agglomerates as shown in Figure 6 - 11. Similar observation was observed when unburned aluminium 
content was found to be significantly decrease as the operating pressure was increased, quench distance is increased; hence the reduction in accumulation and agglomerate size.

\section{Effect of pressure on agglomerate diameter}

The results show the dependence of agglomerate size on pressure.

1) At low pressure, the fine AP particles of the pocket propellant fail to be established near the surface flamelets, resulting in unfavorable conditions for the ignition of the accumulating aluminum and hence formation of large agglomerates.

2) As pressure increased the fine AP particles would establish individual flamelets conducive to aluminum ignition, with a corresponding reduction in accumulation and agglomerate size. This trend in agglomerate size with pressure is conspicuous in Figure 6 - 11. 
Table 2

Experimental data and Predicted data from ANN for P1 Propellant

\begin{tabular}{|c|c|c|c|c|}
\hline $\begin{array}{l}\text { Pressure, } \\
\text { MPa }\end{array}$ & $\begin{array}{c}\text { Quench Distance, } \\
\text { mm }\end{array}$ & $\begin{array}{c}\text { Experimental } \\
\text { Agglomerate } \\
\text { Diameter, } \\
\mu \mathrm{m}\end{array}$ & $\begin{array}{c}\text { Predicted } \\
\text { Agglomerate } \\
\text { Diameter, } \\
\mu \mathrm{m}\end{array}$ & $\begin{array}{c}\text { Percentage } \\
\text { error }\end{array}$ \\
\hline \multicolumn{5}{|c|}{ Training Set } \\
\hline 2 & 5 & 114.8 & 112.84 & 1.70644599 \\
\hline 2 & 23 & 102.7 & 104.38 & -1.6338851 \\
\hline 2 & 35 & 90.2 & 92.02 & -2.01330377 \\
\hline 2 & 47 & 77.1 & 77.04 & 0.0843061 \\
\hline 2 & 71 & 55.2 & 54.62 & 1.05978261 \\
\hline 4 & 5 & 100.5 & 101.29 & -0.78706468 \\
\hline 4 & 23 & 92.6 & 92.71 & -0.11663067 \\
\hline 4 & 35 & 82.6 & 80.44 & 2.61501211 \\
\hline 4 & 47 & 68.2 & 68.31 & -0.1627566 \\
\hline 4 & 71 & 46.2 & 47.25 & -2.27705628 \\
\hline 6 & 5 & 89.7 & 90.72 & -1.1393534 \\
\hline 6 & 23 & 85.1 & 82.92 & 2.5640423 \\
\hline 6 & 35 & 71.3 & 71.46 & -0.22720898 \\
\hline 6 & 47 & 62.6 & 61.76 & 1.34345048 \\
\hline 6 & 71 & 41.8 & 41.20 & 1.42822967 \\
\hline 8 & 5 & 81.9 & 82.55 & -0.78998779 \\
\hline 8 & 23 & 76.5 & 75.61 & 1.1620915 \\
\hline 8 & 35 & 63.2 & 65.07 & -2.95411392 \\
\hline 8 & 47 & 56.7 & 56.60 & 0.17989418 \\
\hline 8 & 71 & 31.8 & 32.04 & -0.76100629 \\
\hline \multicolumn{5}{|c|}{ Testing Set } \\
\hline 2 & 59 & 67.3 & 67.89 & -0.87964339 \\
\hline 4 & 59 & 59.7 & 59.43 & 0.45226131 \\
\hline 6 & 59 & 51.4 & 52.34 & -1.82490272 \\
\hline 8 & 59 & 45.8 & 45.15 & 1.42139738 \\
\hline
\end{tabular}


Table 3

Experimental data and Predicted data from ANN for P2 Propellant

\begin{tabular}{|c|c|c|c|c|}
\hline $\begin{array}{l}\text { Pressure, } \\
\text { MPa }\end{array}$ & $\begin{array}{c}\text { Quench Distance, } \\
\text { mm }\end{array}$ & $\begin{array}{c}\text { Experimental } \\
\text { Agglomerate } \\
\text { Diameter, } \mu \mathrm{m}\end{array}$ & $\begin{array}{c}\text { Predicted } \\
\text { Agglomerate } \\
\text { Diameter, } \\
\mu \mathrm{m}\end{array}$ & $\begin{array}{c}\text { Percentage } \\
\text { Error }\end{array}$ \\
\hline \multicolumn{5}{|c|}{ Training Set } \\
\hline 2 & 5 & 136.1 & 134.97 & 0.83027186 \\
\hline 2 & 23 & 127.6 & 126.565 & 0.81112853 \\
\hline 2 & 35 & 119.9 & 117.681 & 1.85070892 \\
\hline 2 & 59 & 97.7 & 96.094 & 1.64380757 \\
\hline 2 & 71 & 83.8 & 85.438 & -1.9546539 \\
\hline 4 & 5 & 118.8 & 121.998 & -2.6919192 \\
\hline 4 & 23 & 106.4 & 106.694 & -0.2763158 \\
\hline 4 & 35 & 97.9 & 96.671 & 1.25536261 \\
\hline 4 & 59 & 80.6 & 77.76 & $\mathbf{3 . 5 2 3 5 7 3 2}$ \\
\hline 4 & 71 & 70.9 & 64.73 & 8.70239774 \\
\hline 6 & 5 & 102.9 & 101.37 & 1.48688047 \\
\hline 6 & 23 & 89.2 & 89.337 & -0.1535874 \\
\hline 6 & 35 & 73.8 & 81.381 & -10.272358 \\
\hline 6 & 59 & 54.6 & 59.548 & -9.0622711 \\
\hline 6 & 71 & 46.1 & 47.767 & -3.6160521 \\
\hline 8 & 5 & 91 & 87.326 & 4.03736264 \\
\hline 8 & 23 & 77 & 74.716 & 2.96623377 \\
\hline 8 & 35 & 64.9 & 63.859 & 1.60400616 \\
\hline 8 & 59 & 47.8 & 47.261 & 1.12761506 \\
\hline 8 & 71 & 37.9 & 37.837 & 0.16622691 \\
\hline \multicolumn{5}{|c|}{ Testing Set } \\
\hline 2 & 47 & 106.6 & 106.921 & -0.3011257 \\
\hline 4 & 47 & 90.3 & 87.856 & 2.70653378 \\
\hline 6 & 47 & 65.2 & 70.389 & -7.958589 \\
\hline 8 & 47 & 57.6 & 56.535 & 1.84895833 \\
\hline
\end{tabular}


Table 4

Experimental data and Predicted data from ANN for P3 Propellant

\begin{tabular}{|c|c|c|c|c|}
\hline Pressure, MPa & $\begin{array}{c}\text { Quench Distance, } \\
\text { mm }\end{array}$ & $\begin{array}{c}\text { Experimental } \\
\text { Agglomerate } \\
\text { Diameter, } \\
\mu \mathrm{m}\end{array}$ & $\begin{array}{c}\text { Predicted } \\
\text { Agglomerate } \\
\text { Diameter, } \mu \mathrm{m}\end{array}$ & $\begin{array}{l}\text { Percentage } \\
\text { error }\end{array}$ \\
\hline \multicolumn{5}{|c|}{ Training Set } \\
\hline 2 & 23 & 78.1 & 77.2526 & 1.085019206 \\
\hline 2 & 35 & 71.5 & 72.3513 & -1.190629371 \\
\hline 2 & 47 & 65.7 & 65.4332 & 0.40608828 \\
\hline 2 & 59 & 56.8 & 58.4969 & -2.9875 \\
\hline 2 & 71 & 48.9 & 50.2393 & -2.738854806 \\
\hline 4 & 23 & 71.7 & 70.2152 & 2.070850767 \\
\hline 4 & 35 & 63.1 & 64.4562 & -2.149286846 \\
\hline 4 & 47 & 54.9 & 57.5277 & -4.786338798 \\
\hline 4 & 59 & 49 & 49.315 & -0.642857143 \\
\hline 4 & 71 & 42.5 & 41.5174 & 2.312 \\
\hline 6 & 23 & 65.8 & 63.5636 & 3.398784195 \\
\hline 6 & 35 & 57.7 & 56.618 & 1.875216638 \\
\hline 6 & 47 & 48.7 & 48.4479 & 0.517659138 \\
\hline 6 & 59 & 42.5 & 40.8402 & 3.905411765 \\
\hline 6 & 71 & 36.4 & 35.1528 & 3.426373626 \\
\hline 8 & 23 & 57.8 & 55.7579 & 3.533044983 \\
\hline 8 & 35 & 48.9 & 47.6308 & 2.595501022 \\
\hline 8 & 47 & 41.3 & 40.2088 & 2.642130751 \\
\hline 8 & 59 & 35 & 34.7309 & 0.768857143 \\
\hline 8 & 71 & 30.6 & 31.117 & -1.689542484 \\
\hline \multicolumn{5}{|c|}{ Testing Set } \\
\hline 2 & 5 & 85.1 & 85.2814 & -0.213160987 \\
\hline 4 & 5 & 78.5 & 78.7529 & -0.322165605 \\
\hline 6 & 5 & 70.5 & 71.9004 & -1.986382979 \\
\hline 8 & 5 & 65.5 & 65.6354 & -0.206717557 \\
\hline
\end{tabular}


Table 5

Experimental data and Predicted data from ANN for P4 Propellant

\begin{tabular}{|c|c|c|c|c|}
\hline $\begin{array}{l}\text { Pressure, } \\
\text { MPa }\end{array}$ & $\begin{array}{l}\text { Quench Distance, } \\
\text { mm }\end{array}$ & $\begin{array}{l}\text { Experimental } \\
\text { Agglomerate } \\
\text { Diameter, } \mu \mathrm{m}\end{array}$ & $\begin{array}{l}\text { Predicted } \\
\text { Agglomerate } \\
\text { Diameter, } \mu \mathrm{m}\end{array}$ & $\begin{array}{l}\text { Percentage } \\
\text { Error }\end{array}$ \\
\hline \multicolumn{5}{|c|}{ Training Set } \\
\hline 2 & 5 & 67 & 66.2411 & 1.132687 \\
\hline 2 & 23 & 62.1 & 62.447 & -0.55878 \\
\hline 2 & 47 & 50.2 & 50.603 & -0.80279 \\
\hline 2 & 59 & 46.1 & 45.686 & 0.898048 \\
\hline 2 & 71 & 41.7 & 42.0275 & -0.78537 \\
\hline 4 & 5 & 62.4 & 62.8876 & -0.78141 \\
\hline 4 & 23 & 56.4 & 57.5202 & -1.98617 \\
\hline 4 & 47 & 45.9 & 45.8319 & 0.148366 \\
\hline 4 & 59 & 41.5 & 41.4826 & 0.041928 \\
\hline 4 & 71 & 37.5 & 37.0193 & 1.281867 \\
\hline 6 & 5 & 57.6 & 57.2297 & 0.642882 \\
\hline 6 & 23 & 51.5 & 51.2148 & 0.553786 \\
\hline 6 & 47 & 40.7 & 41.2163 & -1.26855 \\
\hline 6 & 59 & 36 & 36.7122 & -1.97833 \\
\hline 6 & 71 & 31.7 & 31.6994 & 0.001893 \\
\hline 8 & 5 & 51.8 & 51.8362 & -0.06988 \\
\hline 8 & 23 & 46.1 & 46.2632 & -0.35401 \\
\hline 8 & 47 & 37.2 & 36.731 & 1.260753 \\
\hline 8 & 59 & 31.9 & 31.7812 & 0.372414 \\
\hline 8 & 71 & 28.1 & 28.2659 & -0.59039 \\
\hline \multicolumn{5}{|c|}{ Testing Set } \\
\hline 2 & 35 & 57.8 & 57.0844 & 1.238062 \\
\hline 4 & 35 & 51.1 & 51.5624 & -0.90489 \\
\hline 6 & 35 & 47.2 & 45.9355 & 2.679025 \\
\hline 8 & 35 & 41 & 41.5381 & -1.31244 \\
\hline
\end{tabular}


Table 6

Experimental data and Predicted data from ANN for P5 Propellant

\begin{tabular}{|c|c|c|c|c|}
\hline $\begin{array}{l}\text { Pressure, } \\
\text { MPa }\end{array}$ & $\begin{array}{c}\text { Quench Distance, } \\
\text { mm }\end{array}$ & $\begin{array}{l}\text { Experimental } \\
\text { Agglomerate } \\
\text { Diameter, } \mu \mathrm{m}\end{array}$ & $\begin{array}{c}\text { Predicted } \\
\text { Agglomerate } \\
\text { Diameter, } \\
\mu \mathrm{m}\end{array}$ & $\begin{array}{c}\text { Percentage } \\
\text { error }\end{array}$ \\
\hline \multicolumn{5}{|c|}{ Training Set } \\
\hline 2 & 5 & 77.5 & 77.549 & -0.06323 \\
\hline 2 & 35 & 62.3 & 62.7043 & -0.64896 \\
\hline 2 & 47 & 56.2 & 56.1226 & 0.137722 \\
\hline 2 & 59 & 50.4 & 49.4414 & 1.901984 \\
\hline 2 & 71 & 42.7 & 43.7155 & -2.37822 \\
\hline 4 & 5 & 70.7 & 70.6693 & 0.043423 \\
\hline 4 & 35 & 55.9 & 55.5076 & 0.701968 \\
\hline 4 & 47 & 46.9 & 47.9385 & -2.21429 \\
\hline 4 & 59 & 44.4 & 43.1075 & 2.911036 \\
\hline 4 & 71 & 38.4 & 39.2598 & -2.23906 \\
\hline 6 & 5 & 65 & 64.8941 & 0.162923 \\
\hline 6 & 35 & 48.1 & 48.2105 & -0.22973 \\
\hline 6 & 47 & 42.3 & 42.8399 & -1.27636 \\
\hline 6 & 59 & 40.3 & 39.5834 & 1.778164 \\
\hline 6 & 71 & 35.6 & 35.0404 & 1.57191 \\
\hline 8 & 5 & 60.1 & 60.126 & -0.04326 \\
\hline 8 & 35 & 44.8 & 44.604 & 0.4375 \\
\hline 8 & 47 & 40.4 & 40.107 & 0.725248 \\
\hline 8 & 59 & 35.5 & 35.8426 & -0.96507 \\
\hline 8 & 71 & 30.6 & 30.547 & 0.173203 \\
\hline \multicolumn{5}{|c|}{ Testing Set } \\
\hline 2 & 23 & 70.5 & 70.1652 & 0.474894 \\
\hline 4 & 23 & 63.4 & 63.9337 & -0.8418 \\
\hline 6 & 23 & 58.4 & 58.1434 & 0.439384 \\
\hline 8 & 23 & 52.9 & 52.8296 & 0.133081 \\
\hline
\end{tabular}


Table 7

Experimental data and Predicted data from ANN for P6 Propellant

\begin{tabular}{|c|c|c|c|c|}
\hline $\begin{array}{c}\text { Pressure, } \\
\text { MPa }\end{array}$ & $\begin{array}{c}\text { Quench Distance, } \\
\text { mm }\end{array}$ & $\begin{array}{c}\text { Experimental } \\
\text { Agglomerate } \\
\text { Diameter, } \mu \mathrm{m}\end{array}$ & $\begin{array}{c}\text { Predicted } \\
\text { Agglomerate } \\
\text { Diameter, } \\
\mu \mathrm{m} \\
\end{array}$ & $\begin{array}{c}\text { Percentage } \\
\text { error }\end{array}$ \\
\hline \multicolumn{5}{|c|}{ Training Set } \\
\hline 2 & 5 & 20.8 & 20.6568 & 0.688462 \\
\hline 2 & 23 & 19.3 & 19.4955 & -1.01295 \\
\hline 2 & 35 & 18.7 & 18.4163 & 1.517112 \\
\hline 2 & 47 & 17 & 17.2689 & -1.58176 \\
\hline 2 & 59 & 16.4 & 16.2438 & 0.952439 \\
\hline 4 & 5 & 20.1 & 20.2393 & -0.69303 \\
\hline 4 & 23 & 18.5 & 18.7469 & -1.33459 \\
\hline 4 & 35 & 17.5 & 17.3774 & 0.700571 \\
\hline 4 & 47 & 16 & 15.938 & 0.3875 \\
\hline 4 & 59 & 14.9 & 14.6722 & 1.528859 \\
\hline 6 & 5 & 18.6 & 18.5841 & 0.085484 \\
\hline 6 & 23 & 16.9 & 16.5795 & 1.89645 \\
\hline 6 & 35 & 14.8 & 15.1262 & -2.20405 \\
\hline 6 & 47 & 13.8 & 13.8523 & -0.37899 \\
\hline 6 & 59 & 12.6 & 12.8602 & -2.06508 \\
\hline 8 & 5 & 16.1 & 16.2392 & -0.8646 \\
\hline 8 & 23 & 14.9 & 14.6775 & 1.493289 \\
\hline 8 & 35 & 13.6 & 13.5461 & 0.396324 \\
\hline 8 & 47 & 12.4 & 12.4982 & -0.79194 \\
\hline 8 & 59 & 11.7 & 11.665 & 0.299145 \\
\hline \multicolumn{5}{|c|}{ Testing Set } \\
\hline 2 & 71 & 15.4 & 15.4069 & -0.04481 \\
\hline 4 & 71 & 13.5 & 13.663 & -1.20741 \\
\hline 6 & 71 & 12.3 & 12.0921 & 1.690244 \\
\hline 8 & 71 & 11.1 & 11.1417 & -0.37568 \\
\hline
\end{tabular}

Figure 6 shows the experimental versus predicted agglomerate diameter of P1 propellant. This trained network had a maximum error of less than $3 \%$. From Figure 6, it is seen that it is possible to extrapolate for any quench distance up to $100 \mathrm{~mm}$ and predict the agglomerate diameter for different values of operating 
pressure. The maximum percentage error in testing set data for P1 propellant is 1.82 which is lesser than $2 \%$.

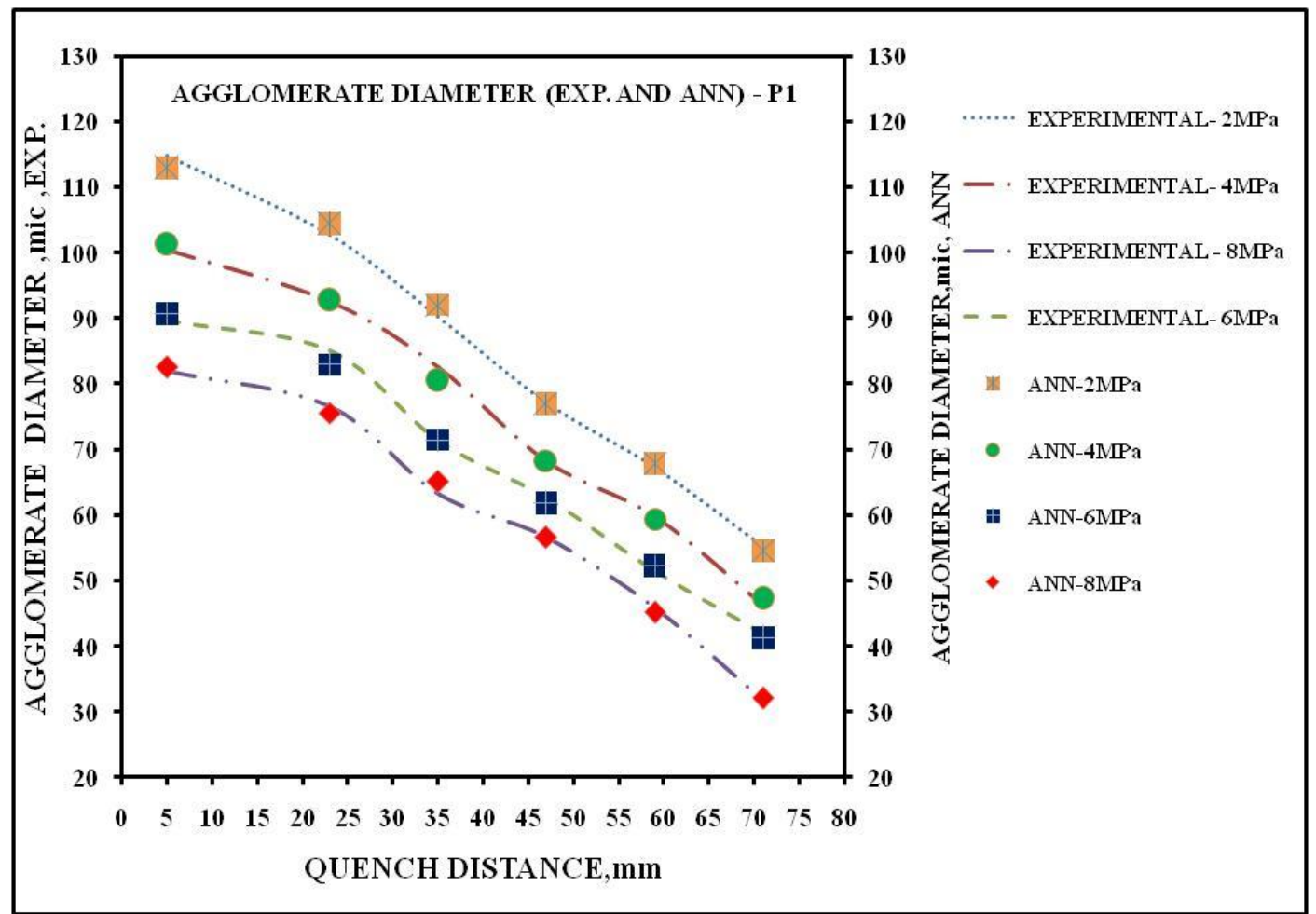

Figure 6. Experimental versus ANN Predicted Agglomerate diameter of P1 propellant.

Figure 7 shows the experimental versus predicted agglomerate diameter of P2 propellant. This trained network had a maximum error of $8.7 \%$ of one value and two values of above $3 \%$ and rest below 3\%. This may be due to the experimental error. The maximum percentage error in testing set data for $\mathrm{P} 2$ propellant is 2.7 which is lesser than $3 \%$. 


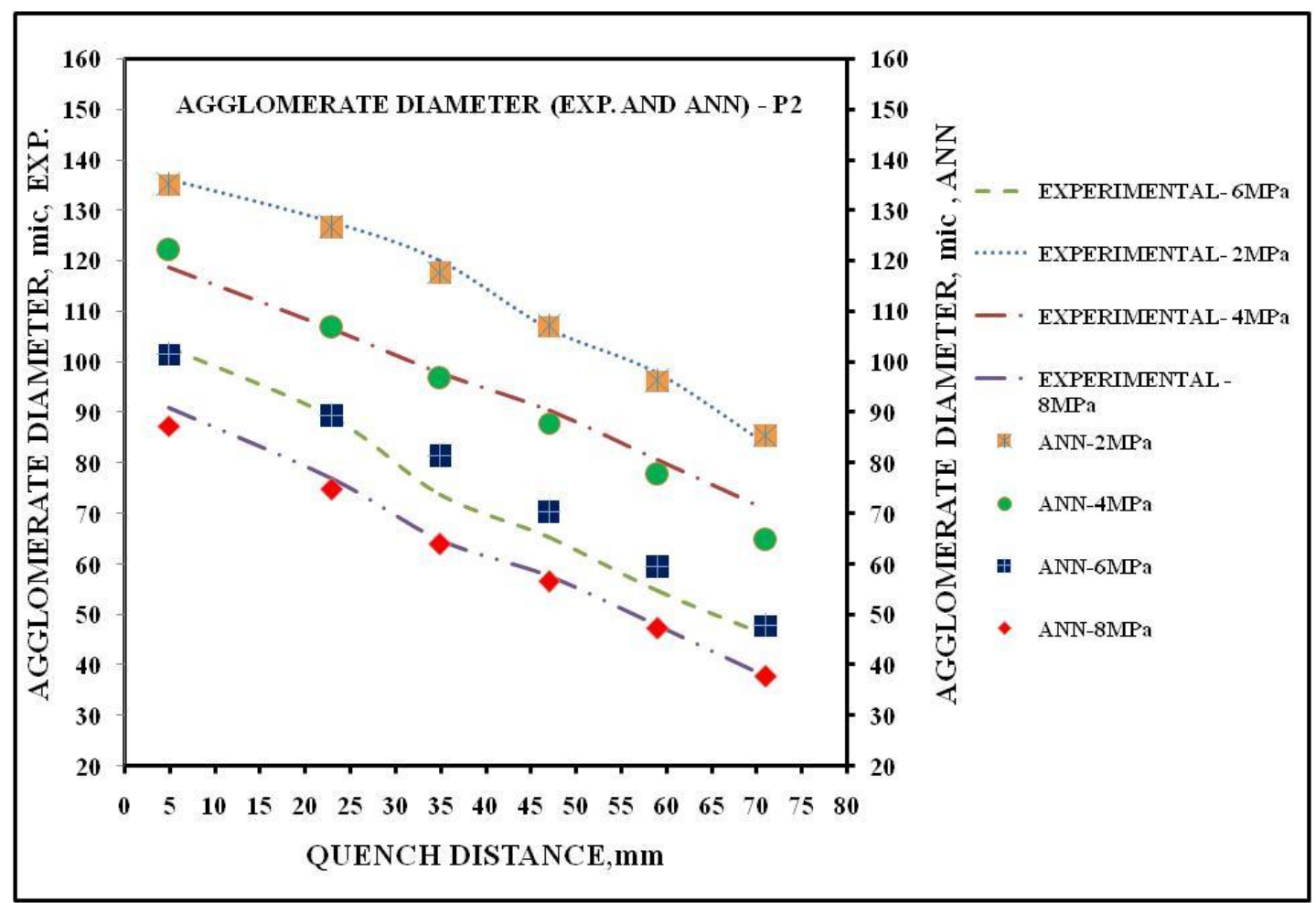

Figure 7. Experimental versus ANN Predicted Agglomerate diameter of P2 propellant.

Figure 8 shows the experimental versus predicted agglomerate diameter of P3 propellant. This trained network had a maximum error of $3.9 \%$ of four values and rest below 3\%. This may be due to the experimental error. The maximum percentage error in testing set data for label 3 propellants is 1.98 which is lesser than $2 \%$. 


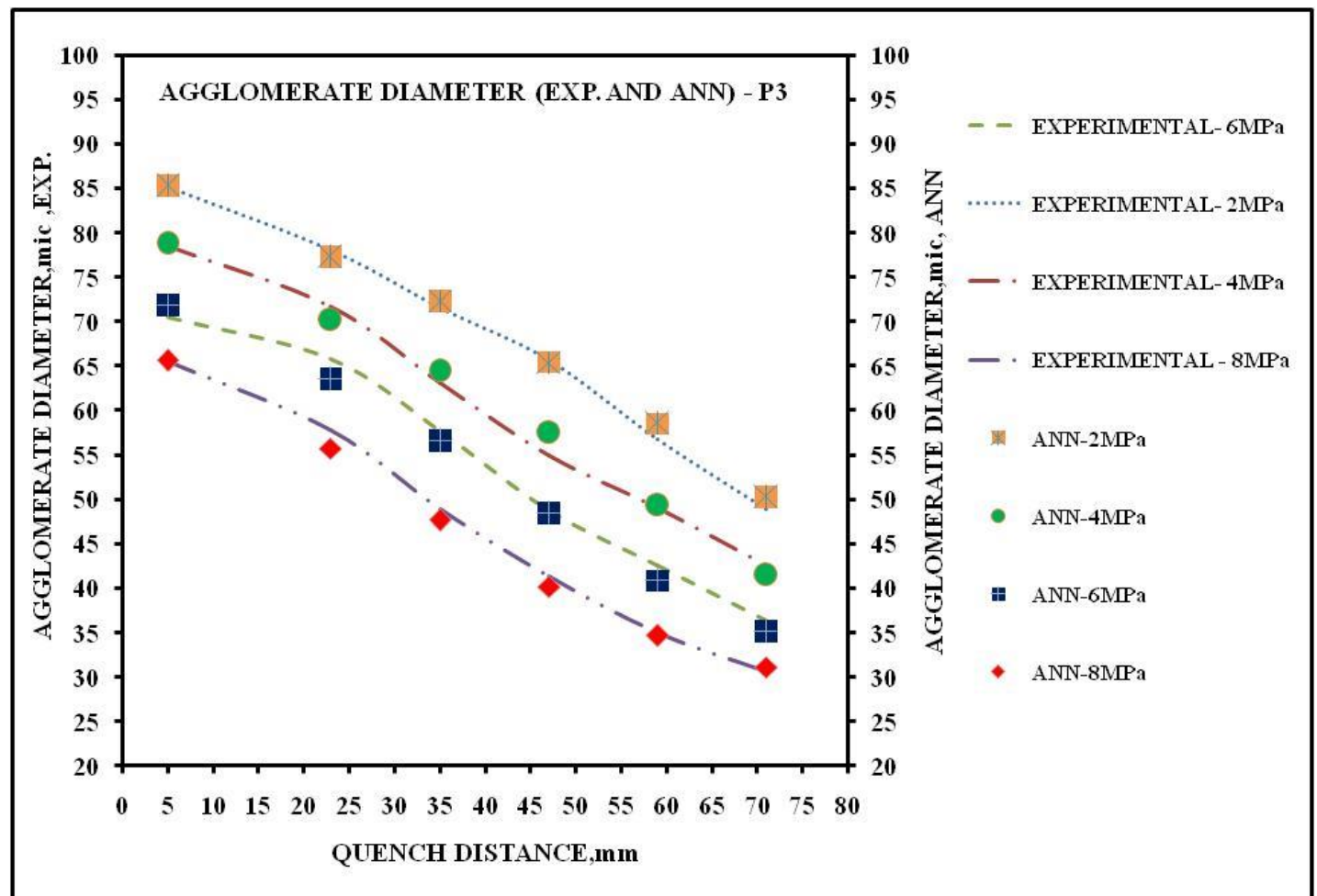

Figure 8. Experimental versus ANN Predicted Agglomerate Diameter of P3 propellant.

Figure 9 shows the experimental versus predicted agglomerate diameter of P4 propellant. This trained network had a maximum error of $1.28 \%$. The maximum percentage error in testing set data for label 4 propellant is 2.67 which is lesser than $3 \%$. 


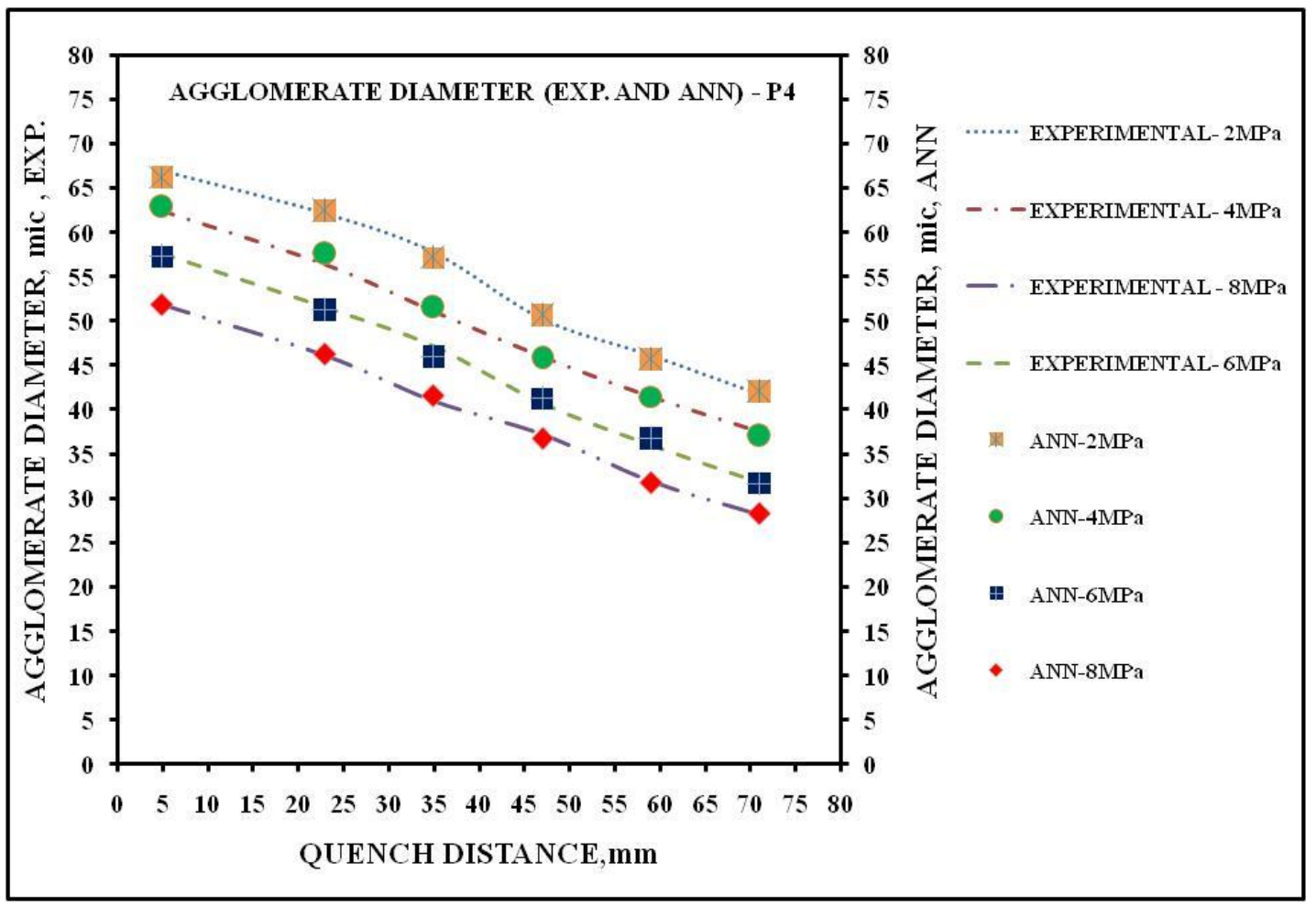

Figure 9. Experimental versus ANN Predicted Agglomerate Diameter of P4 propellant.

Figure 10 shows the experimental versus predicted agglomerate diameter of P5 propellant. This trained network had a maximum error of $2.91 \%$. The maximum percentage error in testing set data for label 5 propellant is 1.82 which is lesser than $0.5 \%$. 


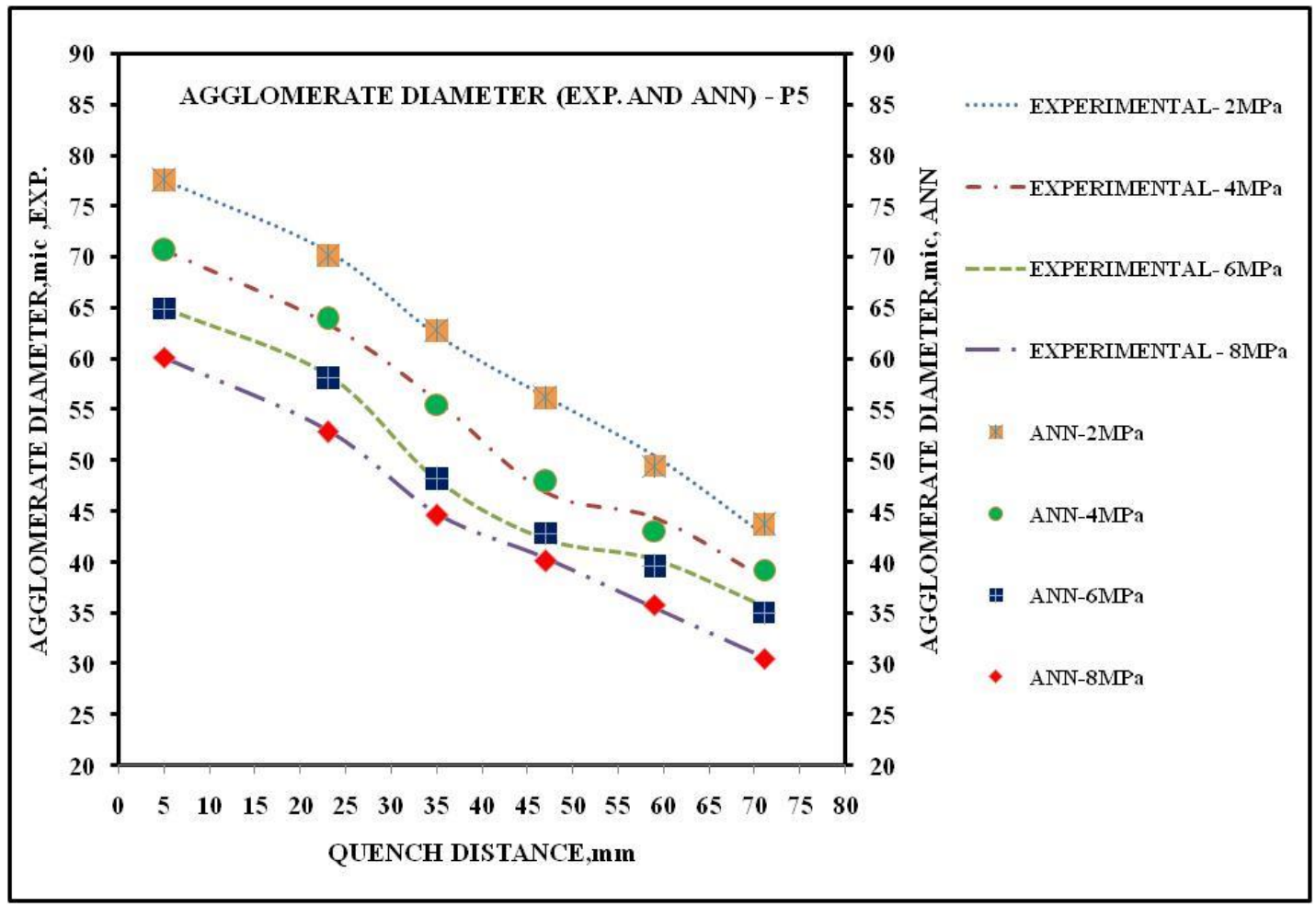

Figure 10. Experimental versus ANN Predicted Agglomerate Diameter of P5 propellant.

Figure 11 shows the experimental versus predicted agglomerate diameter of P6 propellant. This trained network had a maximum error of $1.89 \%$. The maximum percentage error in testing set data for label 6 propellant is 1.69 which is lesser than $2 \%$. 


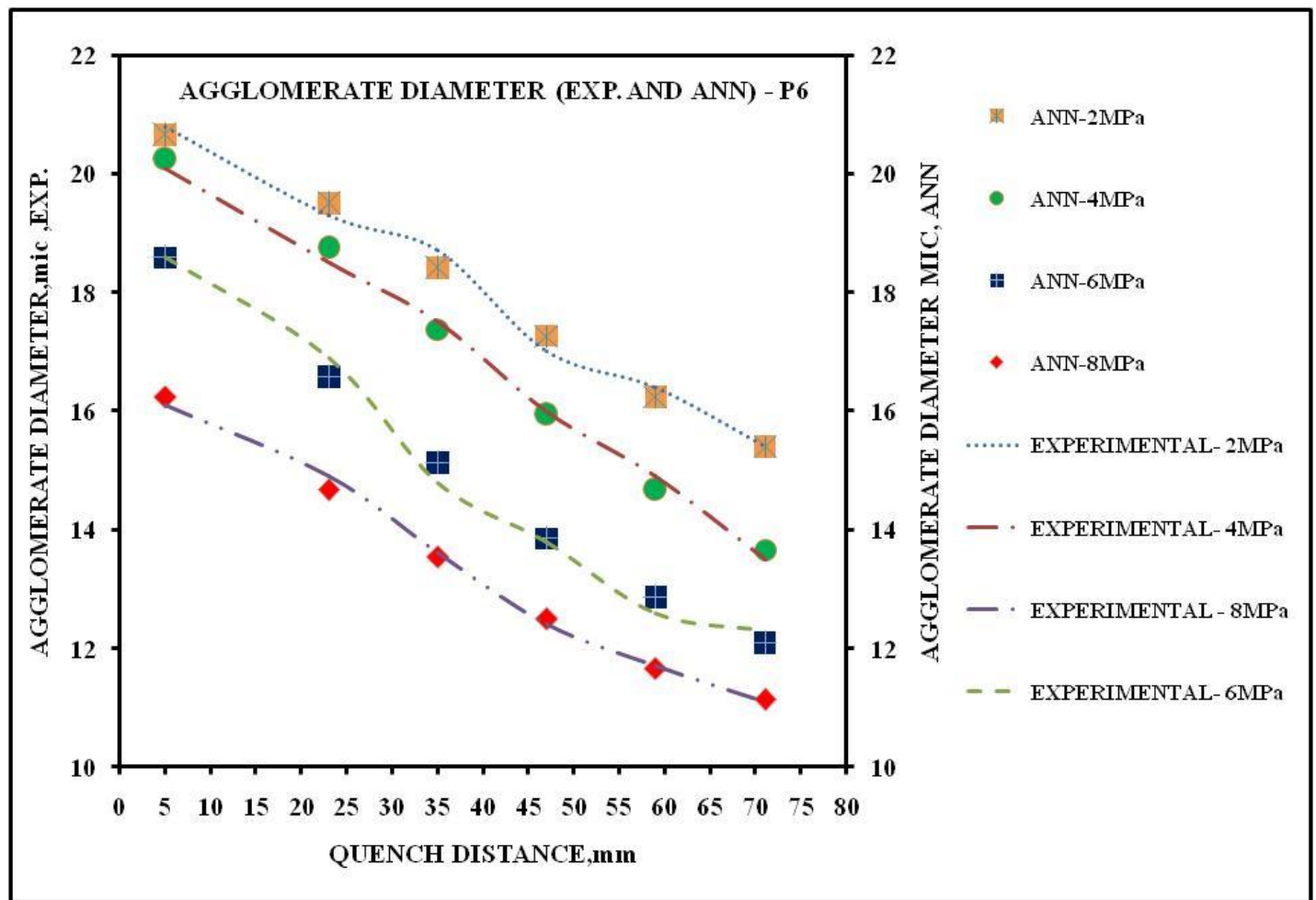

Figure 11. Experimental versus ANN Predicted Agglomerate Diameter of P6 Propellant. 


\section{CONCLUSIONS}

A feasible ANN model has been developed to predict the agglomerate size which is produced by burning of aluminized composite propellants. The agglomerate diameters are evaluated for four different pressures and six quench distances for six propellant formulations. The results show remarkable decrease in agglomerate diameter with increase in pressure and quench distance. Six (6) back propagation neural network architectures are trained and tested based upon mean error percentage until an optimum architecture is identified for each propellant.

The following are evident from this model:

(i) Based on the number architectures that are used to train the ANN model using BP algorithm, the architecture (3-5-10-5-1) was in good agreement to that of the experimental values with the mean squared error less than $3 \%$ for each propellant.

(ii) The developed model can provide beneficial data that can be predicted from the wide range of experimental database. Therefore, time consuming experiments can be reduced and hence considerable savings in terms of cost and time could be obtained by using developed neural network model which serves as a boon for aerospace industry. 


\section{REFERENCES}

Babuk, V. A. (1998). Study of metal agglomeration and combustion, project SPC97-4033-1, final report. Retrieved from https://apps.dtic.mil/dtic/ tr/ fulltext/u2/a550034.pdf

Babuk, V. A., Dolotkazin, I. N., \& Glebov, A. A. (2005). Burning mechanism of aluminized solid rocket propellants based on energetic binders. Propellants, Explosives, Pyrotechnics, 30, 281-290.

Babuk, V. A., Vasilyev, V. A., \& Malakhov, M. S. (1999). Condensed combustion products at the burning surface of aluminized solid propellant. Journal of Propulsion and Power, 15(6), 783-793.

Beckstead, M. W. (1977). A model for solid propellant combustion. Proceedings of the 14th JANNAF Combustion Meeting, Baltimore, MD, 292(1), 281306.

Beckstead, M. W. (2004). A summary of aluminum combustion. NATO RTO, Rhode-Saint-Genese. Retrieved from https://apps.dtic.mil/dtic/tr/ fulltext/u2/a425147.pdf

Beckstead, M. W. (2005). Correlating aluminum burning times. Combustion, Explosion, and Shock Waves, 41(5), 533-546. https://doi.org/10.1007/s10573-005-0067-2

Bucher, P., Ernst, L., \& Dryer, F. L. (2000). Detailed studies on the flame structure of aluminum particle combustion. The American Institute of Aeronautics and Astronautics, 185, 689-722.

Butler, A. G., \&Netzer, D. W. (1988). Holographic investigation of solid propellant combustion. Monterey, CA: Naval Postgraduate School.

Cauty, F., Erades, C., \& Desse, J. M. (2011). Light deviation based optical techniques applied to solid propellant combustion. Progress in Propulsion Physics, 2, 121-134.

Cheung, H., \& Cohen, N. S. (1964). Performance of solid propellants containing metal additives. The American Institute of Aeronautics and Astronautics, $3(2), 250-257$.

Churchill, H. L., Fleming, R. W., \& Cohen, N. S. (1974). Aluminum behavior in solid propellant combustion. AFRPL TR-74-12.

Cohen, N. S. (1983). A pocket model for agglomeration in composite propellants. The American Institute of Aeronautics and Astronautics, 21, 720-725.

De Luca, L. T. (2007). Problemienergetici in propulsioneaerospaziale, Appunti per student. Retrieved from https://www.politesi.polimi.it/bitstream/ 10589/87173/3 /2013_12_Franzin.pdf

De Luca, L. T., Maggi, F., Dossi, S., Weiser, V., Franzin, A., Gettwert, V., \& Heintz, T. (2013). High-energy metal fuel for rocket propulsion: Characterization and performance. Chinese Journal of Explosives and Propellants, 20(6), 1-14. 
Demuth, H. B., Martin, T. H., \& Beale, M. H. (2015). Neural network toolbox user's guide. Retrieved from http://www.academia.edu/34938587/ Neural_Network_Toolbox_Users_GuideThe Math Works, Inc.

Dossi, S. (2010). Effettidellastruttura di fiammasull'agglomerazioneneipropellenti solidi eterogeneialluminizzati. Retrieved from https://www.politesi.polimi.it/ bitstream/ 10589/15281/ 3/2011_03_Dossi.pdf

Faber, D. E., \& Netzer, D. W. (1983). Holographic investigation of solid propellant combustion particulates. Monterey, CA: Naval Postgraduate School.

Gallier, S. (2009). A stochastic pocket model for aluminum agglomeration in solid propellants. Propellants, Explosives, Pyrotechnics,34, 97-105.

Glotov, O. G. (2000). Condensed combustion products of aluminized propellants. II. Evolution of particles with distance from the burning surface. Combustion, Explosion, and Shock Waves, 36(4), 476-487.

Glotov, O. G. (2006). Condensed combustion products of aluminized propellants IV effect of the nature of nitramines on aluminum agglomeration and combustion efficiency. Combustion, Explosion, and Shock Waves, 42, 436-449.

Grigorev, V. G., Kutsenogii, K. P., \& Zarko, V. E. (1981). Model of aluminum agglomeration during the combustion of a composite propellant. Combustion, Explosion, and Shock Waves, 17, 356-363.

Guildenbecher, D. R., Cooper, M. A., Gill, W., Stauffacher, H. L., Oliver, M. S., \& Grasser, T. W. (2014). Quantitative, three-dimensional imaging of aluminum drop combustion in solid propellant plumes via digital in-line holography. Optics Letters, 39(17), 5126-5129.

Haykin, S. (1999). Neural networks: A comprehensive foundation. Upper Saddle River, NJ: Prentice Hall.

Hermsen, R.W. (1999). Aluminum combustion efficiency. The American Institute of Aeronautics and Astronautics, 81, 38.

Jackson, T., Najjar, F., \& Buckmaster, J. (2005). A new class of agglomeration models for aluminum composite propellants based on random packs. Journal of Propulsion and Power, 21, 925-936.

Karasev, V. V., Onischuk, A. A., Glotov, O. G., Baklanov, A. M., Maryasov, A. G., Zarko, V. E., Panfilov, V. N....Sabelfeld, K. K. (2004). Formation of charged aggregates of $\mathrm{Al} 2 \mathrm{O} 3$ nanoparticles by combustion of aluminum droplets in air. Combustion and Flame, 138, 40-54.

Laredo, D., \& Netzer, D. W. (1993). Application of optical diagnostics to particle measurements in solid propellant rocket motors and exhaust plumes.

Particulate Science and Technology, 11, 175-192. 
Laredo, D., McCrorie, J. I., Vaughn, J. K., \& Netzer, D. W. (1994). Motor and plume particle size measurements in solid propellant micrometers. Journal of Propulsion and Power, 10(3), 410-418.

Liu, T. K. (2005). Experimental and model study of agglomeration of burning aluminized propellants. Journal of Propulsion and Power, 21, 797-806.

Liu, T. K., Perng, H. C., Luh, S. P., \& Liu, F. (1992). Aluminum agglomeration in ammonium perchlorate/cyclotrimethylenetrinitramine/aluminum/hydroxy terminated polybutadiene propellant combustion. Journal of Propulsion and Power, 8, 1177-1184.

Povinelli, L. A., \& Rosenstein, R. A. (1964). Alumina size distributions from high-pressure composite solid-propellant combustion. The American Institute of Aeronautics and Astronautics, 2(10),1754-1760.

Mitchell, T. M. (1997). Machine learning. New York, NY: McGraw-Hill.

Patterson, D. W. (1996). Artificial neural networks: Theory and application. Upper Saddle River, NJ: Prentice Hall.

Powers, J. P., \& Netzer, D. W. (1992). Automatic particles sizing from rocket motor holograms. Paper presented to the SPIE Proceedings, San Jose, CA. Retrieved from https://www.semanticscholar.org/paper/In-situ-particlesizing-of-agglomerates-in-solid-(Powell/f6485ccf8038fd2dc8e33233c043eca513e73660/figure/2

Price, E. W. (1965). Experimental solid rocket combustion instability. Symposium (International) on Combustion, 10(1), 1067-1082.

Price, E. W., \& Sigman, R. K. (1999). Combustion of aluminized solid propellants. The American Institute of Aeronautics and Astronautics, 663687. https://doi.org/10.2514/5.9781600866562.0663.0687

Price, E. W., Sigman, R. K., Sambamurthi, J. K., \& Park, C. J. (1982). Behavior of aluminum in solid propellant combustion. Atlanta, GA: Georgia Institute of Technology.

Salita, M. (1994, October). Survey of recent Al2O3 droplet size data in solid rocket chambers, nozzles and plumes. Paper presented at the $31 \mathrm{st}$ JANNAF Combustion Meeting, Sunnyvale, CA.

Sambamurthi, J. K., Price, E. W., \& Sigman, R. K. (1984). Aluminum agglomeration in solid-propellant combustion. The American Institute of Aeronautics and Astronautics, 2(8), 1132-1138.

Scott, G. M., \& Ray, W. H. (1993). Creating efficient nonlinear neural network process model that allow model interpretation. Journal of Process Control, 3(3),163-78. doi:10.1016/0959-1524(93)80022-4

Sippel, T. R., Son, S. R., \&Groven, L. J. (2013). Aluminum agglomeration reduction in a composite propellant using tailored Al/PTFE particles. Combustion and Flame, 161(1), 311-321. 
Sippel, T. R., Son, S. F., Groven, L. J., Zhang, S., \& Dreizin, E. L. (2014). Exploring mechanisms for agglomerate reduction in composite solid propellants with polyethylene inclusion modified aluminum. Combustion and Flame, 162, 846-854.

Walker, J. D., \& Netzer, D. W. (1987). Holographic investigation of metallized solid propellant combustion in two-dimensional and three-dimensional rocket motors. Monterey, CA: Naval Postgraduate School.

Willoughby, P. G., Baker, K. L., \&Hermsen, R. W. (1971, May). Photographic study of solid propellant burning in an acceleration environment. Paper presented at the 13th International Symposium on Combustion, Pittsburgh, PA. 